\title{
Mental Health, Quality of Life and Their Related Factors among Elderly People in Zanjan Health Centers, 2017
}

\author{
Saeideh Mazloomzadeh ${ }^{1}$ (D), Sajjad Biglari ${ }^{2}$ (D) Fatemeh Eskandari $^{\text {1*iD }}$ \\ 1. Social Determinants of Health Research Center, Zanjan University of Medical Sciences, Zanjan, Iran \\ 2. School of Medicine, Zanjan University of Medical Sciences, Zanjan, Iran
}

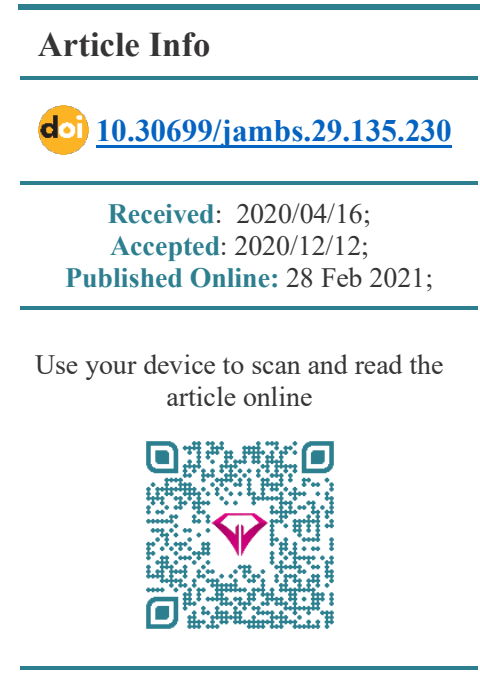

Corresponding Information: Fatemeh Eskandari,

Social Determinants of Health Research Center, Zanjan University of Medical Sciences, Zanjan, Iran

E-Mail: : Faes418@zums.ac.ir

\section{ABSTRACT}

Background \& Objective: Attention to the mental health status of the elderly and their quality of life (QOL) is essential and an important factor in economic progress. The purpose of this study was to determine the mental health status, QOL, and their related factors in the elderly referred to health centers in Zanjan, Iran in 2017.

Materials \& Methods: This cross-sectional study was performed on 228 elderly people referred to Zanjan health centers. Information was collected using two standardized questionnaires, including GHQ-28 and SF-36. The samples were selected using a random cluster sampling method and through considering the socioeconomic status of urban areas. Data was analyzed by independent t-test, ANOVA, Mann-Whitney, and Kruskal-Wallis tests.

Results: Of 228 participants, $61.8 \%$ were female and $38.2 \%$ were male. The mean age of the participants was $68.03 \pm 5.89$. The mean and standard deviation of total mental health was $56.93 \pm 10.27$ (a lower score indicates a better status) and the mean and standard deviation of total QOL score was $58.60 \pm 15.62$. There was a significant relationship between mental health and sex $(P=0.002)$, education $(P=0.01)$, occupation $(P<0.0001)$, and income $(P=0.006)$. Moreover, a significant association was observed between the QOL and variables such as age $(P=0.001)$, education ( $P=0.006)$, occupation $(P=0.001)$, type of residence $(P=0.02)$, and income $(P=0.002)$. In addition, there was a significant correlation between all domains of QOL and mental health $(P<0.001)$.

Conclusion: The results indicated that both mental health status and QOL in this elderly population were in moderate level. Therefore, providing educational and counselling services and comprehensive support from various support systems in the community is recommended.

Keywords: Mental health, Quality of life, Elderly

\section{Introduction}

Old age is a period of life that usually begins around 65 years after being born (1). Changes that occur in the shape and function of the internal and external organs of the body (senescence) cause problems in the acclimatization of the elderly to their environment. Changes in metabolism result in decreased neuromuscular activity and some changes in the appearance of organs. Old age is not considered a disease, but rather an inevitable stipulation of life (2).

Based on the results of the national census organized by the Iranian center of statistics, the average life expectancy has reached 67 years and the population of over 65 -yearold people was reported to be $3.1 \%$ in $1986,4.4 \%$ in 1996 , $5.2 \%$ in $2006,5.7 \%$ in 2011 , and $6.1 \%$ in 2016 . One of the important concerns regarding aging is health. Old age is usually associated with a growing reduction of physical function and the occurrence of mental illness (3).
Mental health is one of the most important foundations of a beneficial, effective, and productive individual, and the promotion of mental health in local communities is essential to the advancement of society. Since physical and social atmosphere affects the social experiences, mental health, development, and adaptation of the elderly, these people often prefer to stay in their own houses, which they deeply depend on, because they remind them of their younger days. The social support that elderly people receive from their family, friends, and neighbors plays a key role in reducing stress (4).

The most common psychological problems of the elderly are depression, anxiety, and dementia. The prevalence of anxiety in the elderly varies from $4 \%$ to $6 \%$. Anxiety can be non-specific, such as in generalized anxiety disorder, or specific, such as in phobias, obsessive-compulsive disorder, and panic attacks. 
Depression also has a high prevalence among psychological disorders of the elderly people. In a large study, $17.8 \%$ of women and $9.4 \%$ of men over the age of 60 were diagnosed with depression based on the fifth diagnostic and statistical manual of mental disorders (DSM-5) (5).

Although the main challenge of public health in the $20^{\text {th }}$ century was increasing the duration of life, it seems that the greater challenge being presented is increasing the quality of life (QOL). The World Health Organization (WHO) describes QOL as "an individual's perception of one's place in life according to the cultural context and the value system of the community which he/she lives in", and this concept is a combination of psychological state, physical health, social relationships, level of independence, individual beliefs, and the relationship between these factors and environmental factors. Furthermore, QOL includes both the positive effects of good health and the negative aspects of illness or disability, and physical, psychological, and social functions exist at its core. Health-related QOL in the elderly consists of the ability to perform daily tasks, general sense of health, and the effects of various physical components such as walking, bathing, going to the toilet, praying, eating, talking, listening, in addition to physical illness and pain, psychological factors (such as emotions), and social factors (social function and economic status) (6).

In developing countries, elderly people are respected and enjoy the emotional, psychological, and social support of their families. This has led the politicians of these countries to forget their responsibilities towards the aging population and put it at the expense of their own families. The high percentage of disabled elderly individuals distresses families with many economic, social, health, and medical dilemmas (7).

As age increases, the use of hospital services, outpatient services, and medications increases. Studies show that age groups under the age of 14 and over 65 years of age have the highest treatment costs. Older people pay more visits to health care centers and the average cost of providing services to these people is higher than other age groups (8).

Most of the studies performed in Iran about the elderly have been based on the elderly living in nursing facilities. According to the results of these studies, the elderly living in these facilities had poorer mental health and the disruption of social function in women was less than in men. Hope also has an effective role in mental health $(2$, 4). Since no study has assessed the status of mental health and QOL in the elderly living in Zanjan so far, this study was conducted to determine the QOL and mental health status of the elderly people referred to health centers in Zanjan, to better plan future health programs aimed at these individuals.

\section{Materials and Methods}

This cross-sectional study was performed on 228 elderly people in the age range of 60 to 80 years in 2017 , who were referring to health centers in Zanjan, Iran. At first, six of 14 health centers were selected using a random cluster sampling method and through considering the socioeconomic status of urban areas so that from each of the regions with high, medium, and low socioeconomic status, two health centers were randomly selected. Then, all samples within each center were entered into the study. The questionnaire was self-report, but for illiterate participants it was completed by a trained questioner. The study was approved by the Ethical Committee of the Zanjan University of Medical Sciences (ZUMS.REC.1395.108).

Data were collected via the General Health Questionnaire (GHQ) and the SF-36 Quality of Life questionnaire. The GHQ questionnaire designed by Goldberg and Hiller in 1972 measures four subscales, including anxiety, depression, physical symptoms, and social function (9). The validity of these questionnaires was reviewed and verified in 1985, 1986, and 1988. In Iran, the validity and reliability of these questionnaires were ascertained by Malakuti et al. (10). The scoring of this questionnaire was based on Likert scale, in which a lower score indicates a better mental health status. The SF-36 questionnaire measures 8 scales related to individual health, four scales related to physical and the other four scales related to mental health. All the 36 questions are organized in the form of eight scales including physical function, role impairment due to physical health, role impairment due to emotional health, emotional well-being, energy/fatigue, pain, general health, and social function; each question has a score between 0 (the lowest score) and 100 (the highest score) (11). Based on the response of the participants, a score is assigned to the individual by summarizing the individual scores acquired for the questions of each structure. The validity of this questionnaire has been confirmed by Montazeri et al. and the Cronbach's alpha for its reliability was $0.65(12)$.

The Kolmogorov-Smirnov test was used to assess the distribution of quantitative variables. Values were expressed as numbers (percentages) and mean \pm standard deviation. Comparisons were performed by independent t-test or ANOVA for normally distributed variables, and Mann-Whitney or Kruskal-Wallis test for the nonnormally distributed variables. All statistical analyses were achieved via SPSS PC version 16.0 for Windows (SPSS, Chicago, IL, USA)

\section{Results}

The mean age of participants was $68.03 \pm 5.89$ years and their median age was 67 years. The most common age group was $60-65$ years old $(41.2 \%)$ and $75.9 \%$ of the elderly were married. Moreover, $50.4 \%$ of the participants were illiterate and $57.5 \%$ were housewives. The highest monthly income was between 5,000,000 and 10,000,000 IRR, and $75 \%$ of the elderly lived with their family (Table 1). 
Table 1. Frequency distribution of demographic and socioeconomic variables

\begin{tabular}{|c|c|c|}
\hline Characteristics & n & $\%$ \\
\hline \multicolumn{3}{|l|}{ Gender } \\
\hline $\begin{array}{l}\text { female } \\
\text { male }\end{array}$ & $\begin{array}{l}26 \\
16\end{array}$ & $\begin{array}{l}61.9 \\
38.1\end{array}$ \\
\hline \multicolumn{3}{|l|}{ Age groups } \\
\hline $\begin{array}{l}60-65 \\
66-70 \\
71-75 \\
76-80 \\
\end{array}$ & $\begin{array}{l}94 \\
65 \\
41 \\
28\end{array}$ & $\begin{array}{c}41.2 \\
28.5 \\
18 \\
12.3\end{array}$ \\
\hline \multicolumn{3}{|l|}{ Marital status } \\
\hline $\begin{array}{l}\text { Married } \\
\text { Single } \\
\text { Divorced } \\
\text { widowed }\end{array}$ & $\begin{array}{c}173 \\
4 \\
3 \\
46\end{array}$ & $\begin{array}{c}75.9 \\
1.8 \\
1.3 \\
20.2\end{array}$ \\
\hline \multicolumn{3}{|l|}{ Education } \\
\hline $\begin{array}{c}\text { Illiterate } \\
\text { Primary school } \\
\text { High school } \\
\text { Diploma } \\
\text { Higher }\end{array}$ & $\begin{array}{c}115 \\
79 \\
8 \\
12 \\
10\end{array}$ & $\begin{array}{c}50.4 \\
34.6 \\
3.5 \\
5.3 \\
4.4\end{array}$ \\
\hline \multicolumn{3}{|l|}{ Occupation } \\
\hline $\begin{array}{c}\text { Housewife } \\
\text { Employed } \\
\text { Retired } \\
\text { Self-employment } \\
\text { Farmer } \\
\text { Unemployed }\end{array}$ & $\begin{array}{c}131 \\
1 \\
52 \\
26 \\
1 \\
11\end{array}$ & $\begin{array}{c}57.5 \\
0.4 \\
22.8 \\
11.4 \\
0.4 \\
4.8\end{array}$ \\
\hline \multicolumn{3}{|l|}{ Income (Tomans) } \\
\hline $\begin{array}{c}<=500000 \\
500000-1000000 \\
1000000-1500000 \\
=>1500000\end{array}$ & $\begin{array}{l}69 \\
89 \\
39 \\
13\end{array}$ & $\begin{array}{c}30.3 \\
39.0 \\
17.1 \\
6.6\end{array}$ \\
\hline \multicolumn{3}{|l|}{ Residency } \\
\hline $\begin{array}{c}\text { Alone } \\
\text { With family }\end{array}$ & $\begin{array}{c}57 \\
171\end{array}$ & $\begin{array}{c}23.7 \\
75\end{array}$ \\
\hline
\end{tabular}

Among the components of mental health, depression had the lowest and social function disorder had the highest mean (a lower score indicates a better mental health status). The mean of total mental health score was 54.66 for men and 56.56 for women. Among the components of
QOL, emotional status had the highest mean of 57.72 and mental health had the lowest score with 46.56. The mean of total QOL for men and women was 61.27 and 56.95, respectively (Table 2$)$.

Table 2. Central indexes and dispersion of mental health and quality of life dimensions

\begin{tabular}{|c|c|c|c|c|c|c|}
\hline Variables & Dimensions & Mean & SD & Median & Max & Min \\
\hline \multirow{5}{*}{ Mental health } & Somatic symptoms & 15.19 & 2.86 & 15 & 26 & 10 \\
\hline & Anxiety and sleep disorder & 13 & 4 & 12 & 26 & 7 \\
\hline & Social function disorder & 19.41 & 2.46 & 20 & 27 & 5 \\
\hline & Depression symptoms & 9.56 & 3.47 & 8 & 24 & 7 \\
\hline & Total - Mental Health & 56.93 & 10.27 & 54 & 86 & 32 \\
\hline \multirow{2}{*}{$\begin{array}{c}\text { Physical } \\
\text { Health }\end{array}$} & Physical Functioning (PF) & 54.46 & 28.86 & 55 & 100 & 0 \\
\hline & Role- Physical (RP) & 66.52 & 35.44 & 75 & 100 & 0 \\
\hline
\end{tabular}




\begin{tabular}{|c|c|c|c|c|c|c|c|}
\hline \multicolumn{2}{|c|}{ Variables } & Dimensions & Mean & SD & Median & $\operatorname{Max}$ & Min \\
\hline \multirow{9}{*}{$\begin{array}{l}\text { Quality of } \\
\text { life }\end{array}$} & \multirow{6}{*}{$\begin{array}{l}\text { Mental } \\
\text { Health }\end{array}$} & Bodily Pain (BP) & 60.30 & 23.91 & 57.50 & 100 & 0 \\
\hline & & General Health (GH) & 50.80 & 19.69 & 50 & 100 & 5 \\
\hline & & Vitality (VT) & 51.36 & 15.51 & 50 & 90 & 15 \\
\hline & & Social Functioning (SF) & 65.07 & 23.58 & 62.50 & 100 & 0 \\
\hline & & Role- Emotional (RE) & 72.57 & 36.30 & 100 & 100 & 0 \\
\hline & & Mental Health (MH) & 46.56 & 15.09 & 44 & 88 & 12 \\
\hline & \multicolumn{2}{|c|}{ Total - Physical Health } & 58.29 & 22.94 & 60.62 & 99 & 2 \\
\hline & \multicolumn{2}{|c|}{ Total - Mental Health } & 59.16 & 12.69 & 60.38 & 92 & 22 \\
\hline & \multicolumn{2}{|c|}{ Total - Quality of Life } & 58.60 & 15.62 & 60.27 & 92 & 14 \\
\hline
\end{tabular}

There was a significant relationship between mental health and sex, and men had a better mental health status than women $(P=0.002$, Table 3$)$. There was also a significant association between mental health and education, occupation, and income $(P<0.05)$. Furthermore, QOL showed a significant association with age so that lower age groups had a higher QOL $(P=0.001$, Table 3 ). There was a significant relationship between QOL and such variables as education, occupation, income, and type of residence $(P<0.05)$. In addition, there were significant correlations between all domains of QOL and mental health $(P<0.001$, Table 4$)$.

Table 3 .Comparison of mean mental health and quality of life by study variables

\begin{tabular}{|c|c|c|c|c|}
\hline \multirow{2}{*}{ Characteristics } & \multicolumn{2}{|c|}{ Mental Health } & \multicolumn{2}{|c|}{ Quality of Life } \\
\hline & Mean \pm SD & $\mathbf{P}$ & Mean \pm SD & $\mathbf{P}$ \\
\hline \multicolumn{5}{|l|}{ Gender } \\
\hline $\begin{array}{c}\text { female } \\
\text { male }\end{array}$ & $\begin{array}{l}58.26 \pm 10.213 \\
54.66 \pm 10.047\end{array}$ & 0.002 & $\begin{array}{l}56.95 \pm 14.87 \\
61.27 \pm 16.51\end{array}$ & 0.05 \\
\hline \multicolumn{5}{|l|}{ Age groups } \\
\hline $\begin{array}{l}60-65 \\
66-70 \\
71-75 \\
76-80\end{array}$ & $\begin{array}{l}54.95 \pm 9.95 \\
56.39 \pm 9.35 \\
60.11 \pm 11.42 \\
60.16 \pm 10.43\end{array}$ & 0.05 & $\begin{array}{l}61.41 \pm 15.005 \\
61.86 \pm 16.233 \\
52.34 \pm 13.465 \\
51.63 \pm 14.952\end{array}$ & 0.001 \\
\hline \multicolumn{5}{|l|}{ Marital status } \\
\hline $\begin{array}{l}\text { Married } \\
\text { Single } \\
\text { Divorced } \\
\text { widowed }\end{array}$ & $\begin{array}{c}55.94 \pm 9.88 \\
61.00 \pm 16.26 \\
71.33 \pm 17.67 \\
59.19 \pm 10.06\end{array}$ & 0.08 & $\begin{array}{l}59.84 \pm 15.26 \\
50.97 \pm 30.09 \\
56.17 \pm 13.74 \\
54.87 \pm 16.54\end{array}$ & 0.28 \\
\hline \multicolumn{5}{|l|}{ Education } \\
\hline $\begin{array}{c}\text { Illiterate } \\
\text { Primary school } \\
\text { High school \&Higher }\end{array}$ & $\begin{array}{c}58.88 \pm 10.85 \\
55.06 \pm 8.61 \\
54.64 \pm 11.04\end{array}$ & 0.01 & $\begin{array}{l}55.17 \pm 16.430 \\
61.94 \pm 13.172 \\
63.42 \pm 17.051\end{array}$ & 0.006 \\
\hline \multicolumn{5}{|l|}{ Occupation } \\
\hline $\begin{array}{c}\text { Housewife } \\
\text { Retired } \\
\text { Self-employment } \\
\text { Unemployed }\end{array}$ & $\begin{array}{c}58.88 \pm 10.23 \\
53.00 \pm 9.42 \\
53.35 \pm 8.58 \\
65.33 \pm 9.91\end{array}$ & $01 \cdot<0$ & $\begin{array}{l}55.93 \pm 15.290 \\
64.07 \pm 15.174 \\
62.37 \pm 11.059 \\
45.59 \pm 25.079\end{array}$ & 0.001 \\
\hline \multicolumn{5}{|l|}{ Income (Tomans) } \\
\hline $\begin{array}{c}<=500000 \\
500000-1000000 \\
1000000-1500000 \\
=>1500000\end{array}$ & $\begin{array}{c}59.54 \pm 10.692 \\
57.12 \pm 10.470 \\
52.77 \pm 8.705 \\
54.14 \pm 9.147\end{array}$ & 0.006 & $\begin{array}{l}54.36 \pm 17.247 \\
57.57 \pm 15.634 \\
64.14 \pm 10.287 \\
68.57 \pm 13.324\end{array}$ & 0.002 \\
\hline
\end{tabular}




\begin{tabular}{ccccc} 
& Mental Health & & \multicolumn{2}{c}{ Quality of Life } \\
Characteristics & Mean \pm SD & P & Mean \pm SD & P \\
Residency & & & & \\
Alone & $59.33 \pm 10.89$ & 0.06 & $60.13 \pm 15.29$ & 0.02 \\
\hline With family & $56.09 \pm 10.02$ & & & \\
\hline
\end{tabular}

Table 4. The correlation among component of mental health and quality of life

\begin{tabular}{|c|c|c|c|c|c|c|c|c|}
\hline \multirow{2}{*}{$\begin{array}{l}\text { Mental Health } \\
\text { Quality of life }\end{array}$} & \multicolumn{2}{|c|}{ Somatic symptoms } & \multicolumn{2}{|c|}{$\begin{array}{c}\text { Anxiety and sleep } \\
\text { disorder }\end{array}$} & \multicolumn{2}{|c|}{$\begin{array}{l}\text { Social function } \\
\text { disorder }\end{array}$} & \multicolumn{2}{|c|}{ Depression symptoms } \\
\hline & $\mathbf{r}$ & P-Value & $\mathbf{r}$ & P-Value & $\mathbf{r}$ & P-Value & $\mathbf{r}$ & P-Value \\
\hline Physical Functioning (PF) & -0.498 & $<0.001$ & -0.500 & $<0.001$ & -0.346 & $<0.001$ & -0.450 & $<0.001$ \\
\hline Role- Physical (RP) & -0.465 & $<0.001$ & -0.468 & $<0.001$ & -0.360 & $<0.001$ & -450 & $<0.001$ \\
\hline Bodily Pain (BP) & -0.581 & $<0.001$ & -0.571 & $<0.001$ & -0.425 & $<0.001$ & -0.498 & $<0.001$ \\
\hline General Health (GH) & 0.812 & $<0.001$ & 0.870 & $<0.001$ & 0.629 & $<0.001$ & 0.852 & $<0.001$ \\
\hline Vitality (VT) & 0.385 & $<0.001$ & 0.445 & $<0.001$ & 0.281 & $<0.001$ & 0.532 & $<0.001$ \\
\hline Social Functioning (SF) & -0.486 & $<0.001$ & -0.506 & $<0.001$ & -0.442 & $<0.001$ & -0.498 & $<0.001$ \\
\hline Role- Emotional (RE) & -0.436 & $<0.001$ & -0.434 & $<0.001$ & -0.372 & $<0.001$ & -0.453 & $<0.001$ \\
\hline Mental Health (MH) & 0.221 & 0.001 & 0.211 & 0.002 & 0.125 & 0.066 & 0.299 & $<0.001$ \\
\hline Physical Health & -0.604 & $<0.001$ & -0.640 & $<0.001$ & -0.472 & $<0.001$ & -0.556 & $<0.001$ \\
\hline Mental Health & -0.334 & $<0.001$ & -0.357 & $<0.001$ & -0.314 & $<0.001$ & -0.280 & $<0.001$ \\
\hline
\end{tabular}

\section{Discussion}

The results of this study revealed that the mean score of mental health among the elderly was 56.93 , which is at a moderate level; but the mean score of mental health was 23.59 in the study by Momeni et al., which is better than ours (a lower score indicates a better mental health status). However, in the study by Abdollahi et al., the mental health score was 67.95, which is worse than our study. This difference could be due to the different samples used. In our study, elderly patients completed questionnaires in urban health centers, but in the study by Momeni et al. the samples were acquired from parks and mosques $(13,14)$.

Among the components of mental health in our study, the mean score of depression among elderly people indicated mild depression, which was consistent with the results of Momeni et al. (13). In the study by Abdollahi et al., the depression rate in the elderly living at home was consistent with our study, but the elderly living in nursing homes reported higher rates of depression (14). The mean score of anxiety in this study is indicative of a moderate prevalence and was much higher than the study conducted by Momeni et al., but lower than the study by Abdolahi et al. In this study, among the components of mental health, social function of the elderly was in a state of alert and indicated a problem in interpersonal relationships, which was not consistent with the results of Momeni et al. and Abdollahi et al.. The contrast is that in the first study, depression and in the latter, depression and physical symptoms were in a state of alert. In our study, depression had the lowest mean and social function had the highest mean, which is in accord with the study by Shirbegi et al., which analyzed mental health in active and inactive elderly people in Ilam, Iran (15). In a study conducted on elderly in Italy, the importance of supporting elderly people, to establish social relationships and in turn reduce loneliness, was mentioned as a major contributor to primary prevention and recovery (16).

The relationship between mental health and demographic, social, and economic variables showed that the mean score of mental health in elderly men was better than that of elderly women, which was consistent with the studies carried out by Mortazavi et al., and Barati et al. $(17,18)$. In our study, mental health was significantly associated with education level so that participants with higher education had better mental health; this finding was also reported in other studies (17, 18). Mental health was also significantly associated with occupation and income so that the unemployed had poorer mental health and older people with higher income had better mental health. In the study by Barati et al. (18), elderly people who were economically independent had better mental health, 
which is somehow consistent with the results of our study. In our study, married individuals had a better mental health score than singles and widows, though it was statistically at the borderline $(P=0.08)$. Other studies also reported a better mental health for the married elderly people (Mortazavi 17 and Barati et al. 18). Therefore, low education level, poverty, and loneliness among the elderly are important factors affecting the mental health of this group.

Based on the findings of this study, the mean total score of QOL among the elderly was moderate (58.6). The study by Habibi et al., which was performed on the elderly people of west Tehran using a short form questionnaire (SF12), revealed a moderate QOL (19). In our study, the mean of QOL was higher in elderly men than in elderly women, but this difference was not significant. In the study by de Frias et al. (20), no significant relationship was found between the physical and mental aspects of QOL and sex. However, in the study performed by Habibi et al., the QOL in men was significantly better than women (19). Similar results have also been observed in other studies $(21,22,23)$. In the study of Borglin (24), women reported more pains and fatigue than men, possibly due to less physical activity among elderly women.

In this study, there was a relationship between QOL and the level of education so that the elderly with a higher educational level had a better QOL. In the studies carried out by Habibi et al. (19), Sari et al., (21), and de Frias et al. (20), higher education was a positive factor for improving QOL (22). Moreover, in the study by Panagioti et al., education and health education were identified for controlling disease and subsequently improving the QOL (25). In this study, a significant association between job type and income with QOL was observed, which was also mentioned in the study by Habibi et al. (19) so that higher incomes were correlated with promotion of healthy behaviors and QOL.

A significant relationship was observed between the type of residence and QOL in our study so that the elderly living alone had a lower QOL than those who lived with their family. In the study by Gerino et al., loneliness was a factor affecting QOL, and older people with more social interactions were less lonely, and the reduction of loneliness could be a major clinical contributor to primary prevention and recovery. Methods used to reduce anxiety levels include increasing flexibility and self-efficacy and reducing dissatisfaction. A high degree of flexibility helps to increase QOL at both physical and mental levels while reducing symptoms of anxiety and depression (16).

In our study, among the components of QOL, physical function scores were relatively high, while physical pain and social function were relatively low, which was in agreement with the results of the study conducted by Gerber et al., in South Africa (26). It has been reported that illnesses in the elderly cause pain and probably affect their performance and social interactions. It seems that as age increases, diseases and disabilities develop; therefore, attention to supportive factors and the empowerment of the elderly is critical in improving their QOL. Significant correlations were also observed between all domains of QOL and mental health in our study, which are in accord with the results of the study by Yektatalab et al., (27). One limitation of our study could be generalization, due to being limited to elderly patients referred to health centers.

\section{Conclusion}

The results of this study indicated that the mental health status of the elderly people was moderate and depression and social function disorder had the highest and the lowest scores, respectively. Furthermore, QOL among the elderly was moderate, and emotional and mental health had the highest and lowest scores, respectively. Mental health among the elderly showed a significant relationship with sex, education, occupation, and income, and the QOL of the elderly had a significant relationship with age, education, occupation, income, and type of residence. Providing educational and counseling services and comprehensive support from various support systems in the community is recommended to improve QOL in the elderly.

\section{Acknowledgments}

This article is based on a research project developed by the Social Determinants of Health Research Center of Zanjan University of Medical Sciences. The authors of this article express their appreciation to the deputy of Research and Technology in the Zanjan University of Medical Sciences for funding this effort.

\section{Conflict of Interest}

The authors declared no conflict of interest.

\section{References}

1. WHO. Aging and life course.2008. Available From: http: //www.who.int/ageing/en

2. Momenikh, Karimi H. Comprison genral health in aging home careand non home care. Iran J Age.2010; 5(17):23-29

3. Behnam Vashani H, Vahedian Shahroudi M, Jafarzade Fakhari M. The quality of life of the elderly in Sabzevar, Iran. J Sabzevar Univ Med Sci.2010; 17(3): 213- 217

4. Elahi T, Khosravi R, RashidiRashtabad S, AkhavanA. Hopefulness and mental disorders in the elderly. J Zanjan Univ Med Sci. 2014; 22(92):116-125 
5. CanbazS, Tevpiksunter A, DabakS,Peksen Y. The prevalence of chronic diseases and quality of life in elderly people in Samsun.Turk J Med Sci. 2003 ; 33, 335-40.

6. Naseh L, Heidari M.Relationship between general self-efficacy and quality of life among elderly living in Chaharmahal Bakhtiari nursing homes.Iran J Aging.2015;10(1),1-12

7. Dadkhah A,Elderly care system in America and Japan and provide indicators for strategic planning for aging services in Iran. Iran $\mathrm{J}$ Aging.2007; 2(3): 166 -176

8. Shojaee A, Akbari K, Fadaeevatan R, Azimian M, Ghaffari Sh, Jamali M. The health costs and diseases in medical services insurance organization, Tehran province, 1386 (2008). Iran J Aging. 2012; 6(22), 65-74

9. Alizadeh M, Fakhrzadeh H, Sharifi F, Ghassemi S, Zanjari N, Mohamadiazar M. Comparative study of physical and mental health status of old people in aged groups of 60-64 and 65-69 years old in Tehran metropolitan area. Iran J Diabet Metab. 2013; 13(1):50-61

10. Malakoti K, Mirabzadeh A, Fatollahi P, et al Reliability, validity, factor analysis and GHQ 28 items in Iranian elderly. Iran J Aging.2006; $1(1): 11-21$

11. Ware JE, Kosinski M, Keller SD. SF-36 physical and mental health summary scales:A Users' Manual. Boston: The Health Institute; 1994.

12. Montazeri A, Gashtasebi A, Vahdaninia M.Translation, reliability and validity of Persian tool by SF-36.J Payesh. 2006; 5(1): 49-56

13. Momeni KH, KarimiH.Comparison of mental health of elderly and non-resident elderly in Kermanshah. J Kermanshah Univ Med Sci. 2010; 14(4): 328- 335

14. Abdollahi MH. SeidiZ. Comparison of cognitive status, mental health and quality of life of the elderly living in the homes of the elderly and residents of Tehran .J Health Breeze. 2014; $3(3): 56-64$

15. Shirbeigi M, Esmaili Z, Sarmadi MR, MoradiA. Study and comparing 3 groups of active, passive, and ecotourist old age people on their mental health and happiness living in Ilam city, Iran. Iran J Aging. 2016; 10(4): 40-48

16. Gerino E, Rolle L, Sechi C, Brustia P. Loneliness, resilience, mental health, and quality of life in old age: A structural equation model. Front Psychol. 2017; 8 (14), Open Access [DOI:10.3389/fpsyg.2017.02003]

17. Mortazavi S, Eftekhar Ardebili H, Mohamad K, Dorali Beni R. Assessing the mental health status of elderly in Shahrekord and relationship with sociodemographic factors. Payesh. 2011;10(4):485-492

18. Barati M, Fathi Y, Soltanian AR, Moeini B. Mental health condition and health promoting behaviors among elders in hamadan. Sci J Hamadan Nurs Midwifery Fac. 2012; 20 (3):1222

19. Habibi sola A, Nikpour S, SohbatzadehR,Haghani H. Quality of life in elderly people of west of Tehran. Iran J Nurs Res.2008; 2(7); 29-35

20. DeFrias CM, Whyne E. Stress on health-related quality of life in older adults: the protective nature of mindfulness. Aging Ment Health. 2015; 19(3):201-6 [DOI:10.1080/13607863.2014.924090]

21. Sari N, Kooshiar H, SaeedVaghee, HamedKamelnia. Elderly's quality of life and related factors among nursing home residents in Mashhad, 2013.J Mazandaran Univ Med Sci. 2014; 24(1):243-252

22. Sil P, Roy G S. An analysis of social adjustment among old age people of Bengal. Int J Physical Educat, Sports Health .2016; 3(2): 145-147

23. Jakobsson U, Hallberg R I, Westergren A. Overall and health related quality of life among the oldest old in pain. Qual Life Res. 2004; 13(1): $125-136$

[DOI:10.1023/B:QURE.0000015286.68287.66]

24. Borglin G, Jakobsson U, Edberg AK, Hallberg IR. Self-reported health complaints and their prediction of overall and health-related quality of life among elderly people. Int J Nurs Stud. 2005; 42(2):147-58 [DOI:10.1016/i.ijnurstu.2004.06.003]

25. Panagioti M, Skevington SM, Hann M,et al. Effect of health literacy on the quality of life of older patients with long-term conditions: a large cohort study in UK general practice. Qual Life Res.2018; $\quad 27 \quad$ (5):1257-1268 [DOI:10.1007/s11136-017-1775-2]

26. Gerber A M, Botes R, Mostert A, Vorster A, Buskens E. A cohort study of elderly people in Bloemfontein, South Africa, to determine healthrelated quality of life and functional abilities. S Afr Med J 2016;106(3):298-301 [DOI:10.7196/SAMJ.2016.v106i3.10171]

27. Yektatatalab SH, Ansarfard F. The relationship between mental health and quality of life in patients with asthma. Iran J Psychiatr Nurs. 2014; 2(1):72-81 


\section{How to Cite This Article:}

Mazloomzadeh S, Biglari S, Eskandari F. Mental Health, Quality of Life and Their Related Factors among Elderly People in Zanjan Health Centers, 2017. J Adv Med Biomed Res. 2021; 29 (135) :230-237

\section{Download citation:}

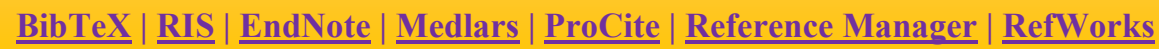

\section{Send citation to:}

(3) Mendeley 2 Zotero ;)RefWorks $\underline{\text { RefWorks }}$ 